\title{
Vesicoureteral Reflux Management With Subureteral Injection of Polydimethylsiloxane in Cases of Recurrent Pyelonephritis in Transplanted Kidneys
}

\author{
Arbey Aristizabal-Alzate ${ }^{a, b}$, Guillermo Salazar-Villac ${ }^{c}$, Carlos Yepes-Delgado ${ }^{b, d}$, \\ Lina Maria Serna-Higuita ${ }^{a, b, f}$, John Fredy Nieto-Rios ${ }^{\mathrm{a}, \mathrm{b}}$, Catalina Ocampo-Kohnn ${ }^{\mathrm{a}, \mathrm{b}}$, Carlos Uribe-Trujillo, \\ Matilde Henao-Velasquez ${ }^{\mathrm{e}}$, Gustavo Zuluaga-Valencia ${ }^{\mathrm{a}, \mathrm{b}}$
}

\begin{abstract}
Background: Kidney graft pyelonephritis is a common complication after renal transplantation, often prompted by vesicoureteral reflux (VUR). An effective and minimally invasive strategy for managing reflux that allows a decrease in the risk of recurrent pyelonephritis is desirable. The aim of this study was to describe our experience with an endoscopic treatment with subureteral injection of polydimethylsiloxane for the treatment of recurrent pyelonephritis of renal grafts secondary to VUR.
\end{abstract}

Methods: Between 2011 and 2016, 17 subureteral polydimethylsiloxane injection procedures were performed. Patient monitoring was done by outpatient consultation and medical record review. The number of pyelonephritis events before and after the procedure and its safety were compared.

Results: Forty-six infection episodes occurred before the procedure (2.71 infections/patient/year) and 10 infection episodes occurred after the procedure (0.59 infections/patient/year), representing a $78.3 \%$ reduction of infections/patient/year. The procedure was well tolerated and safe, with no resultant obstructive complications or changes in renal function and no long-distance migration of the bulking agent detected by monitoring.

Conclusion: Consistent endoscopic treatment with subureteral injection of the bulking agent polydimethylsiloxane to manage VUR in

Manuscript accepted for publication December 28, 2016

aDepartment of Nephrology and Kidney Transplant, Pablo Tobon Uribe Hospital, Medellin, Colombia

${ }^{\mathrm{b}}$ School of Medicine, University of Antioquia (Universidad de Antioquia), Medellin, Colombia

${ }^{\mathrm{c}}$ Department of Internal Medicine, Pontifical Bolivarian University (Universidad Pontificia Bolivariana), Medellin, Colombia

${ }^{\mathrm{d}}$ Department of Epidemiology, Hospital Pablo Tobon Uribe, Medellin, Colombia

eDepartment of Urology, Pablo Tobon Uribe Hospital, Medellin, Colombia ${ }^{f}$ Corresponding Author: Lina Maria Serna-Higuita, Department of Nephrology and Kidney Transplant, Pablo Tobon Uribe Hospital, Calle 78b \# 69-240, Medellin, Colombia. Email: 1m.serna@hotmail.com

doi: https://doi.org/10.14740/wjnu296w cases of recurrent pyelonephritis of kidney grafts is a non-invasive treatment option with a good success rate and safety profile.

Keywords: Renal transplantation; Pyelonephritis; Urinary tract infection; Vesicoureteral reflux; Endoscopic treatment

\section{Introduction}

Urinary tract infections (UTIs), including asymptomatic bacteriuria, cystitis and pyelonephritis, are the most common bacterial infections after renal transplantation [1]. Different studies have shown that bacteriuria and/or cystitis affect up to $50 \%$ of renal transplant patients and are often recurrent [2]. The presence of UTI after renal transplantation has key implications, including the risk of bacteremia and sepsis requiring hospitalization and the need for multiple cycles of antibiotic therapy, which is expensive and may lead to bacterial resistance and contribute to erratic levels of immunosuppression [3]. Conversely, the presence of recurrent UTI leads to renal graft inflammation and subsequent fibrosis [4]. Previous studies have shown that pyelonephritis is associated with reduced renal graft function and an increased risk of loss $[5,6]$.

Vesicoureteral reflux (VUR) of kidney grafts, a complication that develops in 50-86\% of kidney transplant patients [7] and is associated with an eight times higher risk of developing pyelonephritis [8], is among the various risk factors associated with post-transplant pyelonephritis.

Currently, the treatment of choice for symptomatic VUR is open surgical re-implantation $[9,10]$, which has a success rate of $83-100 \%$. However, this is a difficult procedure and has a morbidity rate ranging from $16 \%$ to $53 \%$, supporting the need for less invasive [11-13], simpler, and more cost-effective treatments. Antibiotic prophylaxis is one of the options available to prevent UTI in patients with kidney graft VUR. This strategy decreases the need for surgical intervention, although the risk for UTI persists due to poor adherence to this therapy or the presence of resistant bacteria. Conversely, the use of long-term antibiotics is controversial because of the potential risk for increasing rates of bacterial resistance [14].

Another available option is endoscopic management of 
VUR by subureteral injection. This treatment involves the application of bulking agents in the bladder wall under the ureteral orifice or inside the ureteral tunnel, causing tissue augmentation and thereby decreasing VUR. Various bulking agents, including polytetrafluoroethylene (Teflon), autologous chondrocytes, fibroblasts, fat and bovine collagen injections, have been used [15].

In our renal transplantation group, subureteral injection using polydimethylsiloxane as a bulking agent is the treatment of choice for VUR of kidney grafts and is performed in patients with pyelonephritis secondary to recurrent VUR of kidney grafts. The bulking agent includes the following components: a water-soluble gel (polyvinylpyrrolidone), which is absorbed and eliminated from the body via the urine, and silicone elastomer (cross-linked polydimethylsiloxane), which is a rubberlike, permanent, non-absorbable synthetic implantation material. This non-absorbable material causes the swelling effect after implantation. The aim of this study was to describe our experience with this therapy for the treatment of recurrent pyelonephritis of renal grafts secondary to VUR.

\section{Materials and Methods}

\section{Study population}

This was a retrospective descriptive study conducted at the $\mathrm{Pa}$ blo Tobon Uribe Hospital (Medellin, Colombia). The clinical records of kidney transplant patients diagnosed with kidney graft pyelonephritis with VUR and in whom subureteral injection of polydimethylsiloxane was performed between August 2011 and January 2016 were reviewed.

All evaluated patients received induction therapy with monoclonal (alemtuzumab, basiliximab, and daclizumab) or polyclonal (thymoglobulin) antibodies at the time of transplant; triple immunosuppressive therapy was administered for maintenance, which included a calcineurin inhibitor (tacrolimus or cyclosporine), an antimetabolite (mycophenolate or azathioprine) and prednisolone or a mammalian target of rapamycin (mTOR) inhibitor such as mycophenolate and prednisolone.

The following clinical parameters were evaluated: age, sex, chronic kidney disease etiology, immunosuppressive therapy, complications associated with the subureteral injection procedure, number of pyelonephritis events before and after the procedure, the etiological agent of pyelonephritis, kidney graft survival, serum creatinine values during monitoring and mortality rate. Procedural success was defined by a decrease in the number of pyelonephritis events after subureteral injection. Recurrent pyelonephritis was defined as the presence of two or more episodes of pyelonephritis-like infection episodes after renal transplantation. The diagnosis of VUR of the transplanted kidney was performed by voiding cystourethrography (VCUG). Furthermore, a renal ultrasound was performed in all patients before the procedure to rule out post-void residue as an indicator of bladder dysfunction.

Patient monitoring after subureteral injection was performed by nephrologists from the kidney transplant group un- til March 2016. All data were extracted from medical records and a form designed by the nephrology group at the institution.

\section{Surgical procedure used for renal transplantation}

Kidney grafts were positioned retroperitoneally in almost all cases through an extended inguinal incision. Vascular reconstruction was performed in the external iliac vessels. Ureterovesical anastomosis was performed by direct re-implantation in the bladder dome or using the anti-reflux method described by Lich Gregoir, according to the preference of the surgeon. Placement of the double $\mathrm{J}$ catheter was not a standard procedure in our group. Therefore, the decision was made at the discretion of the surgeon based on the surgical findings. The double $\mathrm{J}$ catheter was usually removed at 3 weeks after renal transplantation.

\section{Description of the subureteral injection procedure}

The endoscopic procedure was performed by the urology group at our institution. Before the procedure, all patients had negative urine culture results. The bulking agent consisted of polydimethylsiloxane, which comprises implants of the silicone elastomer suspended in a polyvinylpyrrolidone matrix. This procedure was performed under general anesthesia in the lithotomy position. Lidocaine jelly was used to lubricate the urethra and pass the 19-Fr rigid cystoscope, which permits identification of the ureteral neomeatus and intra-operative confirmation of the presence of VUR. Subsequently, the endoscopic needle was positioned, and polymer application was performed at $10 \mathrm{o}$ 'clock to assess the formation of a wheal in the ureteral neomeatus and inject, on average, $1.5-2 \mathrm{~cm}$ using a prefilled syringe. Finally, $50 \mathrm{cc}$ of contrast medium was instilled to perform the cystography and assess the absence of VUR. After the procedure, bladder catheterization was performed to quantify urinary output.

\section{Statistical analysis}

The collected data were analyzed using the statistical analysis statistical package SPSS version 20.0 and STATA version 12. Qualitative variables were analyzed by frequency, proportions and rates (\%/person-year). Quantitative variables were expressed as means or medians with their respective standard deviations or quartiles (p25-75) according to the distribution of the data, which was identified based on the Shapiro-Wilk test.

The median age at transplantation, age at procedure, initial and 3, 6 and 12 months post-procedure creatinine levels, time between kidney transplantation and procedure and total monitoring time were determined. Furthermore, the rate of patients who were free from infection post-procedure and the average time in months free from infection were calculated with $95 \%$ confidence intervals (CIs) using the Kaplan-Meier non-parametric test. 
Table 1. Demographic Characteristics and Relevant Data $(n=17)$

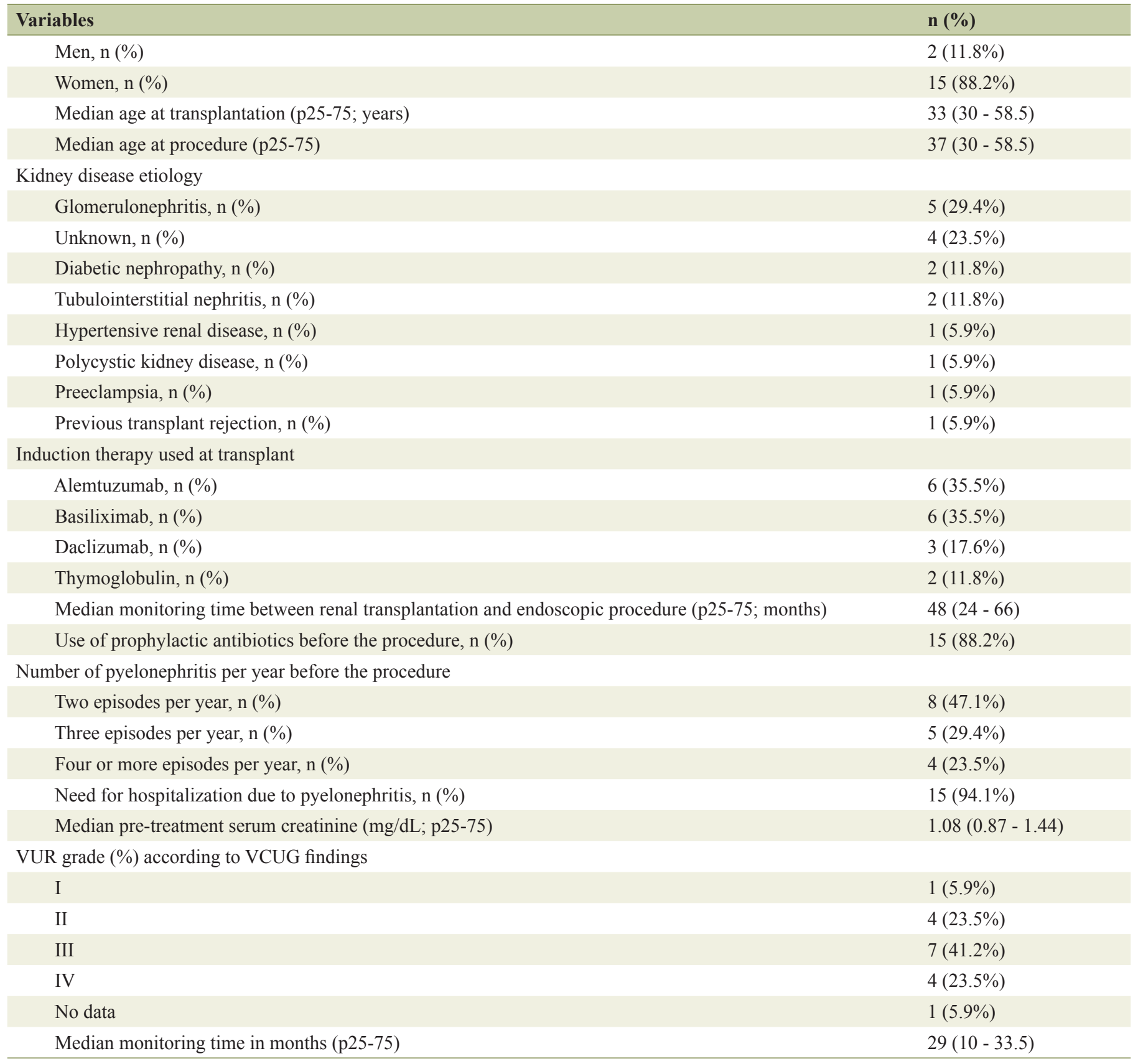

VCUG: voiding cystourethrography.

The rate of reduction in the number of infections/patient/ year before and after the procedure was also calculated, and the statistical significance was assessed using the non-parametric Wilcoxon rank-sum test. An analysis of the dichotomous variable post-procedure-related infection was performed using the McNemar test.

This study was approved by the ethics and research committee of Pablo Tobon Uribe Hospital and followed the ethical standards for research involving human subjects contained in Resolution 008430 (1993) of the Ministry of Health of Colom- bia. Furthermore, the confidentiality of the personal data of all patients included in the study was preserved.

\section{Results}

From August 2011 to January 2016, 332 kidney transplants were performed, among which 17 patients had recurrent pyelonephritis secondary to VUR of the kidney graft (5.1\% incidence) and were considered candidates for subureteral injec- 
Table 2. Patient Progression After the Endoscopic Procedure

\begin{tabular}{|c|c|c|c|}
\hline & Before the procedure & After the procedure & $\mathbf{P}$ \\
\hline Rate of pyelonephritis episodes per year (pyelonephritis episodes/patient-year) & 2.71 & 0.59 & $0.01 *$ \\
\hline Need for antibiotic prophylaxis, $\mathrm{n}(\%)$ & $15(88.2 \%)$ & $8(47.1 \%)$ & $0.039 * *$ \\
\hline Mortality rate & $0(0 \%)$ & $0(0 \%)$ & \\
\hline
\end{tabular}

"Wilcoxon rank-sum test for related samples. ${ }^{* \star}$ McNemar test for related samples.

tion.

\section{Baseline characteristics}

Among the patients, 94.1\% $(n=16)$ received a kidney transplant from a deceased donor, one received a combination liverkidney transplant, and one received his third kidney transplant. The gender distribution was $88.2 \%(\mathrm{n}=15)$ women and $11.8 \%$ $(\mathrm{n}=2)$ men. The median age at the time of transplant was 33 years (p25-75: 30 - 58.5 years) (Table 1). Regarding the surgical method used for renal transplantation, direct ureteral re-implantation was performed in nine patients, the method by Lich Gregoir was applied in five patients, and no data on the type of surgical procedure performed were collected for three patients.

Before the endoscopic procedure, there was a median number of pyelonephritis episodes of 3/year (p25-75: $3-3.5$ years $)$, and $94.1 \%(n=16)$ of patients required hospitalization. The microorganisms responsible for pyelonephritis were, in the largest number of cases, Escherichia coli, followed by Klebsiella pneumoniae and, less frequently, Enterobacter cloacae, Enterococo faecalis, Citrobacter koseri, Citrobacter freundii, Serratia marcescens and Staphylococcus saprophyticus. None of the patients received another form of surgical treatment for VUR. Other patient demographic characteristics are presented in Table 1.

\section{Patient monitoring}

After the endoscopic procedure, five of the 17 patients had new episodes of pyelonephritis, demonstrating a success rate of $70.6 \%$ (free of infection post-procedure). Three patients had episodes of cystitis, albeit without progression to pyelonephritis.

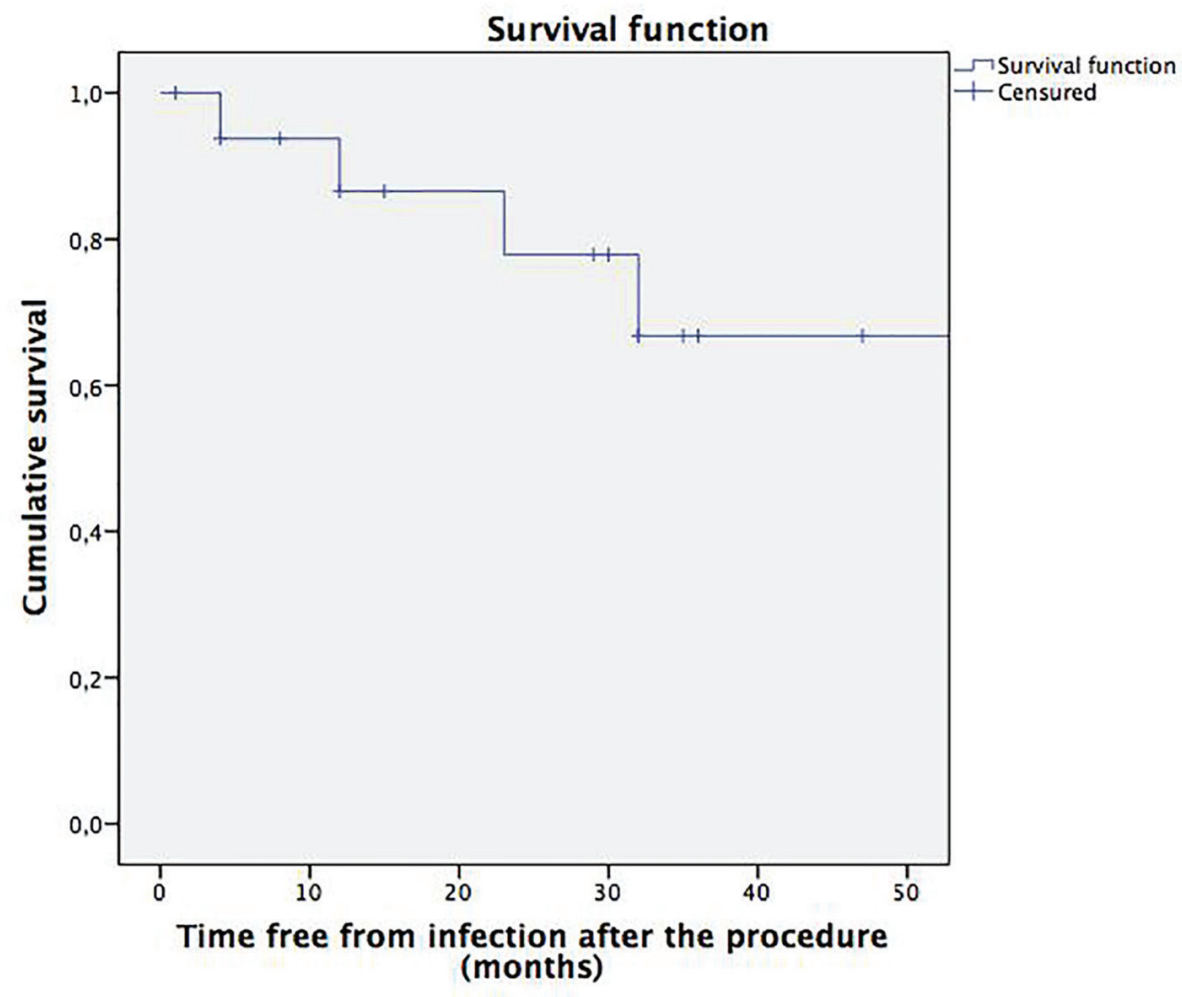

Figure 1. Survival function. Time free from pyelonephritis after the subureteral injection procedure. 


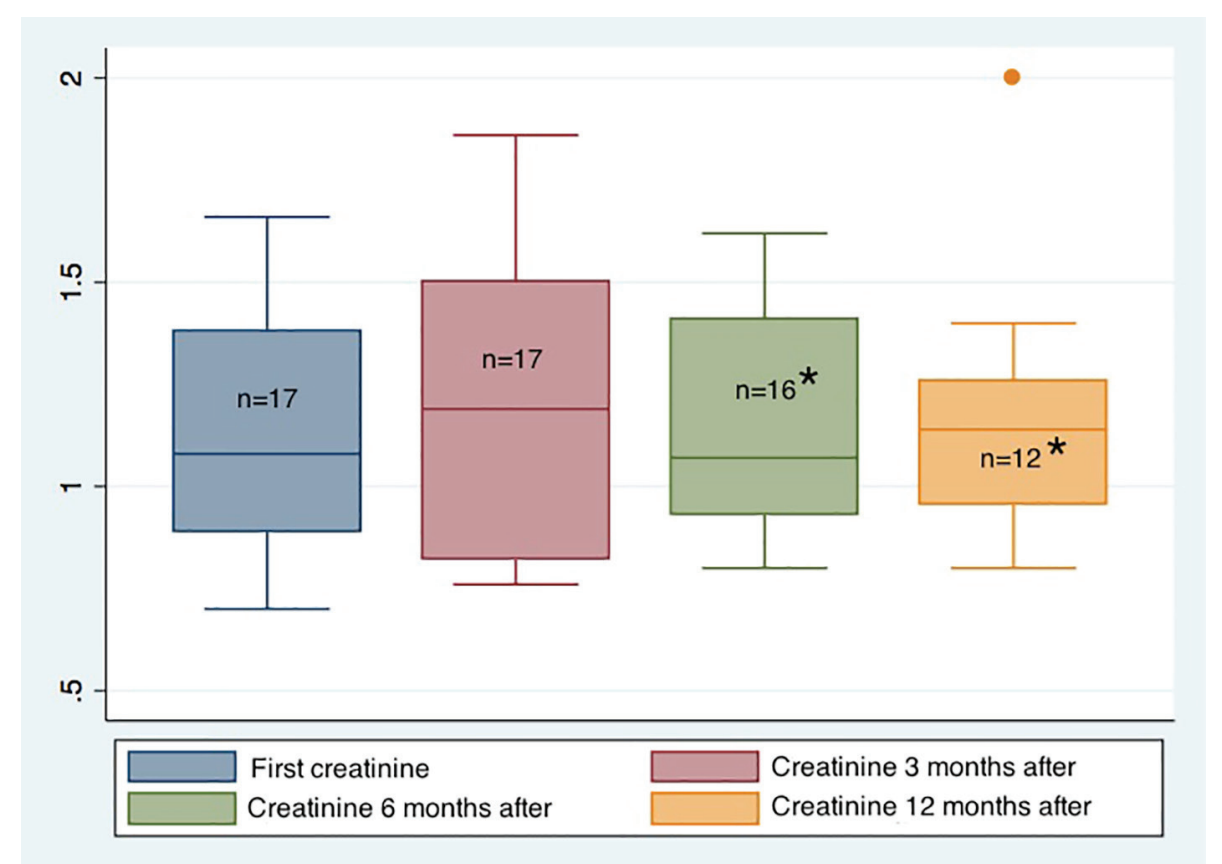

Figure 2. Evolution of renal function before and after the endoscopic procedure. *One patient lost the renal graft during the 6-month monitoring period. Only 12 patients completed 12 months of monitoring after the endoscopic procedure.

Before the procedure, 46 episodes of pyelonephritis had occurred in the 17 evaluated patients; three patients had one episode per year, one patient had four episodes per year, and one patient had three episodes per year. The latter received another polymer Vantris, in addition to polydimethylsiloxane during the procedure, based on the decision of the urologist. The rate of pyelonephritis before the procedure was 2.71 pyelonephritis episodes/patient-year. Ten episodes of infection occurred after the procedure, equating to a rate of 0.59 pyelonephritis episodes/patient-year. This result reveals a $78.2 \%$ decrease in pyelonephritis episodes/patient-year, which was significant $(\mathrm{P}=0.01)($ Table 2$)$.

The analysis of the five patients with pyelonephritis after treatment and their correlation with the VUR grade showed that one patient had VUR grade IV, two patients had VUR grade II, one patient had VUR grade I, and one patient had no information regarding the VUR grade. Among the patients with recurrent episodes of pyelonephritis after the endoscopic procedure, one persisted with VUR grade I, and another persisted with VUR grade II. The average time free from infection post-procedure was 34 months (95\% CI: 24.16 - 44.28) (Fig. $1)$.

Regarding complications associated with the procedure, one patient had transient renal graft dysfunction after the procedure with a subsequent return to pre-procedure serum creatinine levels without kidney graft hydronephrosis. No evidence of long-distance migration of the bulking agent was found.

The median kidney function was $1.19 \mathrm{mg} / \mathrm{dL}$ (p25-75: 0.82 - 1.5), $1.07 \mathrm{mg} / \mathrm{dL}$ (p25-75: 0.93 - 1.43) and $1.14 \mathrm{mg} / \mathrm{dL}$ (p25-75: $0.94-1.28$ ) at 3, 6 and 12 months after the procedure, respectively (Fig. 2).

Only one case of graft loss occurred, which was associ- ated with immunological causes (acute rejection confirmed by biopsy with difficulties in managing the aggressive immunosuppressant for hepatitis $\mathrm{C}$ viral replication in a hepatitis C-positive patient with transplant). The other grafts persisted with adequate renal function. No deaths occurred during the study period.

\section{Discussion}

UTI is a leading cause of infectious complications in kidney transplant recipients and may occur in $25 \%$ of patients; $77 \%$ of UTI cases may be uncomplicated acute bacterial cystitis, although pyelonephritis may occur in $23 \%$ of cases [16]. Pyelonephritis may be favored by the presence of graft VUR, which is common after renal transplantation, with incidence rates ranging from $50 \%$ to $86 \%[7,8]$. Therefore, renal transplant recipients with recurrent UTI, particularly pyelonephritis, should be examined by voiding cystography to rule out VUR.

Reflux is very dependent on the ureteroneocystostomy method used, and many surgeons favor a wide ureteroneocystostomy rather than tunnelled re-implantation to minimize the risk of ureteral stenosis [17].

The significance of reflux in adults after renal transplantation has been debated. Favi et al [18] compared 15 recipients with VUR with 22 recipients without VUR. Each patient had at least one UTI per year. No difference was found in the number of infections per year, serum creatinine levels or patient or graft survival. However, none of the patients had reflux grade IV or V, and $26 \%$ only had reflux grade I. Jung et al [19] published a similar study that included 75 transplant recipients. Among the group with VUR, $61.3 \%$ had reflux grade IV or V. 
Similarly, there were no differences in renal function or rate of urinary tract infection between the two cohorts. However, the monitoring period was shorter than 1 year.

In contrast to previous studies, Mastrosimone et al conducted a study of recipients who were monitored for more than 5 years after renal transplantation. The authors observed a higher incidence of hypertension and a trend towards an increased risk for urosepsis in patients with VUR [8]. Similarly, Pelle et al assessed the impact of UTI and graft pyelonephritis on graft function in 177 renal transplant recipients and observed a significant increase in serum creatinine and a decrease in creatinine clearance, which were detected during the first year and persisted for 4 years post-transplant; however, neither the graft nor patient survival was altered. Multivariate analysis showed that acute pyelonephritis was an independent risk factor associated with the decline in renal function [1]. More recently, Shin et al assessed the impact of early-onset graft pyelonephritis in 265 kidney transplant recipients from January 2001 to December 2011, and they found that early-onset graft pyelonephritis was independently associated with the decline in renal function and, therefore, may be a predictor of the longterm outcome of renal allografts [20].

Regardless of the controversy in the literature, most physicians agree that patients with recurrent UTI or sepsis associated with UTI in the context of high-grade VUR require some type of treatment, which may consist of observation with suppressive antibiotics, endoscopic injection of bulking agents or ureteral re-implantation [21].

The use of prophylactic antibiotics in patients with lowgrade reflux (I-III) is a non-invasive strategy for this population. However, the persistence of new infections, despite prophylaxis or a diagnosis of high-grade VUR, suggests the need for surgical therapy. Open ureteral re-implantation or ureteroureterostomy of the native ipsilateral ureter has been the standard treatment. However, it is an invasive procedure with a potential risk of complications, including ureteral stenosis, urinary fistula, ureteral necrosis and even renal graft loss [17].

Given these risks, a minimally invasive therapy, similar to the endoscopic treatment of VUR, is desirable. The basic treatment principle is to bulk up the ureteral orifice walls to generate ureteral mucosa coaptation during bladder filling and create a valve mechanism to decrease the size of the refluxing orifice. Such treatment is performed with different substances that should be inert, readily injectable and stable over time to prevent the loss or migration of their volume to other tissues. Furthermore, they should be non-toxic, non-carcinogenic, without allergenic potential and biocompatible, resulting in minimal inflammation.

The concept of subureteral injection therapy to treat VUR is not new. The method was first described in 1981 by Matouschek [22], and the first clinical cases were reported in 1984 by O'Donell and Puri [23]. Since then, it has evolved as a viable therapeutic alternative to ureteroneocystostomy [24].

The optimal bulking agent has not been found. Thus, the use of several agents has been reported in the literature, as described below. A material that is commonly used, polytetrafluoroethylene, has a success rate of $85 \%$ [25]; in some cases, particle migration to the brain and lungs to generate a granulomatous reaction has been observed with this material
[26]. Subureteral collagen injection has also been reported, with success rates exceeding $83 \%$ [27]. Collagen difficulties include the need for a skin test because the bovine protein may be allergenic. Furthermore, biodegradation and contraction of the injected collagen may occur, leading to recurrent VUR.

Injectable autologous materials include fat, collagen, chondrocytes and bladder smooth muscle cells. However, these compounds may also undergo biodegradation and contraction and have low success rates [28], limiting their use. Dextranomer/hyaluronic acid is a compound that consists of polysaccharide molecules with dextran, forming microspheres with a diameter ranging from 80 to $120 \mu \mathrm{m}$. In 1995, Stenberg and Lackgren [29] first reported the use of dextranomer/hyaluronic acid copolymer to treat VUR endoscopically. In contrast to other agents, this copolymer displays minimal particle migration and rarely generates an immunogenic response to a foreign body; a 72\% success rate has been reported with it [30].

Previous studies have referred to VUR management in native kidneys until the first series of cases of VUR associated with treated transplants was published in 2007 for dextranomer/hyaluronic acid [31]. The study included four women with VUR and impaired renal function. Reflux resolved after a single injection into one patient and after two treatments in two patients; one patient required open ureteral re-implantation. In 2011, Pichler et al [32] published their experience with dextranomer/hyaluronic acid in a total of 19 recipients who had experienced three or more UTIs per year. Reflux resolved in $57.9 \%$ of the patients after the initial injection, increasing to $78.9 \%$ after two treatments. The authors observed a reduction in the average number of infections per year from 4.89 to 1.31 . Two patients had ureteral obstruction that required nephrostomy. A study by Yucel et al [33] using dextranomer/hyaluronic acid included 26 recipients with a reported overall success rate of $53.8 \%$, which was correlated to the VUR grade. Among the patients, $90 \%$ with VUR grade I and II were cured by an injection compared with $31 \%$ with VUR grade III and IV.

Another compound, Durasphere, consists of zirconium oxide beads coated with pyrolytic carbon that have a low migration potential because of their size (ranging from 251 to $300 \mu \mathrm{m})$. In 2011, Antonopoulos et al [15] used this compound to treat eight transplant patients with recurrent pyelonephritis secondary to VUR, and they reported a $75 \%$ success rate. The silicone elastomer polydimethylsiloxane was recently introduced for the endoscopic treatment of VUR, with success rates exceeding $81.8 \%$ in a non-transplant population $[34,35]$. In a recent study, Akiki et al [36] endoscopically treated VUR in 58 transplanted patients ( 38 women and 20 men), with a $56.1 \%$ overall success rate; one group of patients received dextranomer/hyaluronic acid, and another group received polydimethylsiloxane. The results showed that the dextranomer/hyaluronic acid treatment provided greater effectiveness.

In our study, polydimethylsiloxane was used as the bulking agent. The decision to use this bulking agent was based on its good availability in our hospital setting, our experience using it for vesicoureteral reflux management in the non-transplant population and its good safety profile with no reports of serious adverse events, extrusion, migration or immune reactions [37]. Another bulking compound, polyacrylate polyalcohol with glycerol, was only used in one patient based on the 
decision of the urologist during the surgical procedure.

We demonstrated a $5.1 \%$ symptomatic reflux rate, which is similar to the study by Akiki, albeit higher than the rates reported in the literature ranging from $0.8 \%$ to $3.0 \%$ [38-40]. This finding may be related to the ureteral anastomosis method used in our group, in which the technique of direct re-implantation into the bladder dome predominates in most transplant surgeries versus the anti-reflux method described by Lych Gregoire, although it may also be related to an increased awareness in our group of the possibility of reflux in the presence of recurrent pyelonephritis. Furthermore, a significant decrease in the number of pyelonephritis episodes before and after the procedure was also observed, demonstrating a 70.6\% success rate. This result was very similar to the findings reported by Antonopoulos in 2011, albeit higher than that in other studies conducted in transplant populations. Conversely, there was no relationship between the VUR grade before treatment and the treatment success rate, as described in other studies. In our study, the procedure was safe, and there were no changes in renal function or graft loss related to the procedure or longdistance migration of the bulking agent.

This study has several limitations. This is a retrospective study, which may lead to selection bias. The number of patients was limited. Control voiding cystography was only performed immediately post-treatment and was not performed at longer time points (weeks) after the treatment, which is a limiting factor because bulging may be lost, requiring additional injections to improve the chances of success. This possibility should be considered in future studies.

Despite the limitations, we believe that endoscopic treatment of recurrent pyelonephritis secondary to reflux has an adequate success rate and may be considered a good treatment alternative to open ureteral re-implantation, providing the advantage of being a minimally invasive procedure with low morbidity and, potentially, lower cost. It has become the treatment of choice for recurrent pyelonephritis secondary to VUR in our transplant group, and we will continue to evaluate the associated results and effectiveness.

\section{Acknowledgments}

This work was supported by Hospital Pablo Tobon Uribe, Medellin, Colombia.

\section{Conflicts of Interest}

The authors of this manuscript have no conflicts of interest to disclose as described by nephrology dialysis transplantation.

\section{Consent}

Informed consent from participant included in the study was not obtained, because this was a retrospective descriptive study; furthermore in our renal transplantation group, subureteral injection with polydimethylsiloxane is the treatment of choice for vesicoureteral reflux of kidney grafts. However, the researchers agreed to respect the confidentiality and privacy of information in the clinical records.

\section{Abbreviations}

UTIs: urinary tract infections; VUR: vesicoureteral reflux; mTOR: mammalian target of rapamycin; VCUG: voiding cystourethrography

\section{References}

1. Pelle G, Vimont S, Levy PP, Hertig A, Ouali N, Chassin $\mathrm{C}$, Arlet G, et al. Acute pyelonephritis represents a risk factor impairing long-term kidney graft function. Am J Transplant. 2007;7(4):899-907.

2. Fiorante S, Fernandez-Ruiz M, Lopez-Medrano F, Lizasoain M, Lalueza A, Morales JM, San-Juan R, et al. Acute graft pyelonephritis in renal transplant recipients: incidence, risk factors and long-term outcome. Nephrol Dial Transplant. 2011;26(3):1065-1073.

3. Lorenz EC, Cosio FG. The impact of urinary tract infections in renal transplant recipients. Kidney Int. 2010;78(8):719-721.

4. Ciszek M, Paczek L, Bartlomiejczyk I, Mucha K. Urine cytokines profile in renal transplant patients with asymptomatic bacteriuria. Transplantation. 2006;81(12):16531657.

5. Audard V, Amor M, Desvaux D, Pastural M, Baron C, Philippe R, Pardon A, et al. Acute graft pyelonephritis: a potential cause of acute rejection in renal transplant. Transplantation. 2005;80(8):1128-1130.

6. El-Zoghby ZM, Stegall MD, Lager DJ, Kremers WK, Amer H, Gloor JM, Cosio FG. Identifying specific causes of kidney allograft loss. Am J Transplant. 2009;9(3):527535.

7. Ostrowski M, Wlodarczyk Z, Wesolowski T, Gracz H, Sluzar T, Sienko J, Lubikowski J, et al. Influence of ureterovesical anastomosis technique on the incidence of vesicoureteral reflux in renal transplant recipients. Ann Transplant. 1999;4(1):54-58.

8. Mastrosimone S, Pignata G, Maresca MC, Calconi G, Rabassini A, Butini R, Fandella A, et al. Clinical significance of vesicoureteral reflux after kidney transplantation. Clin Nephrol. 1993;40(1):38-45.

9. Austin JC, Cooper CS. Vesicoureteral reflux: surgical approaches. Urol Clin North Am. 2004;31(3):543-557, x.

10. Krishnan A, Swana H, Mathias R, Baskin LS. Redo ureteroneocystostomy using an extravesical approach in pediatric renal transplant patients with reflux: a retrospective analysis and description of technique. J Urol. 2006;176(4 Pt 1):1582-1587; discussion 1587.

11. Hau HM, Tautenhahn HM, Schmelzle M, Krenzien F, Schoenberg MB, Morgul MH, Uhlmann D, et al. Management of urologic complications in renal transplantation: a single-center experience. Transplant Proc. 2014;46(5):1332-1339. 
12. Lehmann K, Muller MK, Schiesser M, Wildi S, Fehr T, Wuthrich RP, Clavien PA, et al. Treatment of ureteral complications after kidney transplantation with native ureteropyelostomy reduces the risk of pyelonephritis. Clin Transplant. 2011;25(2):201-206.

13. Salomon L, Saporta F, Amsellem D, Hozneck A, Colombel M, Patard JJ, Chopin D, et al. Results of pyeloureterostomy after ureterovesical anastomosis complications in renal transplantation. Urology. 1999;53(5):908-912.

14. Lackgren G, Stenberg A. Endoscopic treatment of vesicoureteral reflux: current practice and the need for multifactorial assessment. Ther Adv Urol. 2009;1(3):131-141.

15. Antonopoulos IM, Piovesan AC, Falci R, Jr., Kanashiro H, Saito FJ, Nahas WC. Transurethral injection therapy with carbon-coated beads (Durasphere(R)) for treatment of recurrent pyelonephritis in kidney transplant patients with vesico-ureteral reflux to the allograft. Clin Transplant. 2011;25(2):329-333.

16. Valera B, Gentil MA, Cabello V, Fijo J, Cordero E, Cisneros JM. Epidemiology of urinary infections in renal transplant recipients. Transplant Proc. 2006;38(8):24142415.

17. Duty BD, Barry JM. Diagnosis and management of ureteral complications following renal transplantation. Asian J Urol [Internet]. Elsevier Ltd; 2015;2(4):202-207. Available from: http:/www.sciencedirect.com/science/article/ pii/S2214388215000855.

18. Favi E, Spagnoletti G, Valentini a. L, et al. Long-Term Clinical Impact of Vesicoureteral Reflux in Kidney Transplantation. Transplant Proc [Internet]. Elsevier Inc.; 2009;41(4):1218-1220.

19. Jung GO, Chun JM, Park JB, Choi GS, Kwon CH, Joh JW, Lee SK, et al. Clinical significance of posttransplantation vesicoureteral reflux during short-term period after kidney transplantation. Transplant Proc. 2008;40(7):23392341.

20. Shin DH, Kim EJ, Lee S, et al. Early-Onset Graft Pyelonephritis Is Predictive of Long-Term Outcome of Renal Allografts. 2015.

21. Duty BD, Conlin MJ, Fuchs EF, Barry JM. The current role of endourologic management of renal transplantation complications. Adv Urol. 2013;2013:246520.

22. Matouschek E. Die behandlung des vesikorenalen Refluxes durch transurethrale Einspritzung von Teflon paste. Urol A. 1981;20:263.

23. O'Donnell B, Puri P. Treatment of vesicoureteric reflux by endoscopic injection of Teflon. 1984. J Urol. 2002;167(4):1808-1809; discussion 1810.

24. Guerra LA, Khanna P, Levasseur M, Pike JG, Leonard MP. Endoscopic treatment of vesicoureteric reflux with Deflux: a Canadian experience. Can Urol Assoc J. 2007;1(1):41-45

25. Puri P, Ninan GK, Surana R. Subureteric Teflon injection (STING). Results of a European survey. Eur Urol. 1995;27(1):71-75.

26. Aaronson IA, Rames RA, Greene WB, Walsh LG, Hasal UA, Garen PD. Endoscopic treatment of reflux: migration of Teflon to the lungs and brain. Eur Urol. 1993;23(3):394-
399.

27. Reunanen M. Correction of vesicoureteral reflux in children by endoscopic collagen injection: a prospective study. J Urol. 1995;154(6):2156-2158.

28. Haferkamp A, Contractor H, Mohring K, Staehler G, Dorsam J. Failure of subureteral bovine collagen injection for the endoscopic treatment of primary vesicoureteral reflux in long-term follow-up. Urology. 2000;55(5):759-763.

29. Stenberg A, Lackgren G. A new bioimplant for the endoscopic treatment of vesicoureteral reflux: experimental and short-term clinical results. J Urol. 1995;154(2 Pt 2):800-803.

30. Kirsch AJ, Perez-Brayfield M, Smith EA, Scherz HC. The modified sting procedure to correct vesicoureteral reflux: improved results with submucosal implantation within the intramural ureter. J Urol. 2004;171(6 Pt 1):24132416.

31. Seifert HH, Mazzola B, Ruszat R, Muller A, Steiger J, Bachmann A, Sulser T. Transurethral injection therapy with dextranomer/hyaluronic acid copolymer (Deflux) for treatment of secondary vesicoureteral reflux after renal transplantation. J Endourol. 2007;21(11):1357-1360.

32. Pichler R, Buttazzoni A, Rehder P, Bartsch G, Steiner H, Oswald J. Endoscopic application of dextranomer/ hyaluronic acid copolymer in the treatment of vesicoureteric reflux after renal transplantation. BJU Int. 2011;107(12):1967-1972.

33. Yucel S, Akin Y, Celik O, Erdogru T, Baykara M. Endoscopic vesicoureteral reflux correction in transplanted kidneys: does injection technique matter? J Endourol. 2010;24(10):1661-1664.

34. Smith DP, Kaplan WE, Oyasu R. Evaluation of polydimethylsiloxane as an alternative in the endoscopic treatment of vesicoureteral reflux. J Urol. 1994;152(4):12211224.

35. Al-Hunayan AA, Kehinde EO, Elsalam MA, Al-Mukhtar RS. Outcome of endoscopic treatment for vesicoureteral reflux in children using polydimethylsiloxane. J Urol. 2002;168(5):2181-2183.

36. Akiki A, Boissier R, Delaporte V, Maurin C, Gaillet S, Karsenty G, Coulange C, et al. Endoscopic treatment of symptomatic vesicoureteral reflux after renal transplantation. J Urol. 2015;193(1):225-229.

37. Ghoniem GM, Miller CJ. A systematic review and metaanalysis of Macroplastique for treating female stress urinary incontinence. Int Urogynecol J. 2013;24(1):27-36.

38. Karam G, Maillet F, Braud G, Battisti S, Hetet JF, Glemain $\mathrm{P}$, Le Normand L, et al. [Surgical complications in kidney transplantation]. Ann Urol (Paris). 2007;41(6):261-275.

39. Masahiko $\mathrm{H}$, Kazunari $\mathrm{T}$, Tokumoto $\mathrm{T}$, Ishikawa $\mathrm{N}$, Yagisawa T, Toma H. Comparative study of urosurgical complications in renal transplantation: intravesical versus extravesical ureterocystoneostomy. Transplant Proc. 2000;32(7):1844-1846.

40. Ranchin B, Chapuis F, Dawhara M, Canterino I, HadjAissa A, Said MH, Parchoux B, et al. Vesicoureteral reflux after kidney transplantation in children. Nephrol Dial Transplant. 2000;15(11):1852-1858. 